\title{
A STUDY OF PLACE VS. RESPONSE BEHAVIOR, LEARNING AND REASONING IN THE WHITE RAT
}

\author{
By $e^{+x}$ \\ LEMING B. CORLIS
}

\begin{abstract}
A DISSERTATION PRESENTED TO THE GRADUATE COUNCIL OF THE UNIVERSITY OF FLORIDA

IN PARTLAL FULFILLMENT OF THE REQUIREMENTS FOR THE DEGREE OF DOCTOR OF PHILOSOPHY
\end{abstract}

UNIVERSITY OF FLORIDA

June, 1958 
UNIVERSITY OF FLORIDA

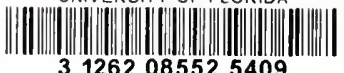

31262085525409 


\section{ACKYOWLEDGWENTS}

The writer is greatly indebted to the many persons whose cooperation and suggestions made this study possible. As it is impossible to mention all of these persons by name, the writer wishes them to know that their assistance is genuinely appreciated.

Special thanks must be offered to Dr. Richard J. Anderson who has been extremely helpful from the very inception of this work. Dr. Rolland H. Waters also contributed many valuable suggestions. The writer wishes to express his thanks to the other members of his comittee, Dr. E. P. Home, Dr. E. D. Hinckley, and Dr. O. B. Thomason. 
ACKNOWLEGLENTS. . . . . . . . . . . . . . . . . ii LIST OF TABLES . . . . . . . . . . . . . . . . iv LIST OF IILUSTRATIONS. . . . . . . . . . . . . . . v v Chapter

I. INTRODUCTION . . . . . . . . . . . . . . 1 I. EXPERIMENTAL DESIGN. . . . . . . . . . . 8 II. RESULTS. .................. IL IV. INTERPRETATION AND DISCUSSION. . . . . . . . . 27 V. SUMMRY. . . . . . . . . . . . . . 33 APPENDIX . . . . . . . . . . . . . . . 35 BIBLIOGRAPHY . . . . . . . . . . . . . . 45 


\section{LIST OF TABLFS}

Table

Page

1. Nean Number of Trials to Criterion on Tasks 1, 2, 3, and 6.................... 15

2. A Comperison of Place vs. Response Learners on Miean

Number of Trials to Criterion on Tasks 1, 2, 3, and 6.16

3. Relations of Reasoning Mieasures on Task 4...... 17

4. Lean Measures for the Anjmals that Reasoned on Task 4 - 18

5. Mean Measures for the Animals that did not Reason on

Task 4................. 18

6. A Comparison of Reasoners and Non-reasoners on the Measures on Task 4.............. 19

7. Data on Mean Number of Trials to Iearning Criterion and Mean Number of Trials to Reasoning on Task 5. . . . 20

8. Type of Behavior Exhibited on the Test Trials of Tasks 1,2 , and 3............... 22

9. Number of Animals Reasoning on Task by Place-Response Category on Tasks 1, 2, and 3........... 23

10. Number of Animals Reasoning by Predominant "Place" or "Response" Behavior on Tasks 1, 2, and 3..... . 23

11. Comparison of Mean Reasoning lleasures on Task 4 and Place-Pesponse Category on Tasks 1, 2, and 3..... 24

12. Mean Number of Trials to Reasoning on Task 5 by PlacePesponse Category on Tasks 1, 2, and 3........ 25

13. Hean Number of Trials to Criterion on Tasks 1, 2, and 3 by Place-Response Category. . . . . . . . 26

14. Mean Number of Trials to Criterion on Task 5 by PlaceResponse Category on Tasks 1, 2, and 3........ 26 
LIST OF ILLUSTRATIONS

Figure

Page

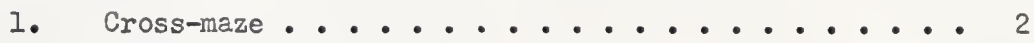

2. Diagram of Tasks 1 and 6 in Room $1 \ldots 36$

3. Diagram of Task 2 in Room 1......... 37

4. Diagram of Task 3 in Room 1............... 38

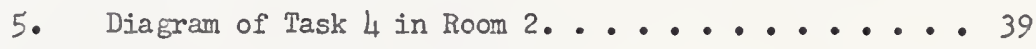

6. Diagram of Task 5 in Room 2......... 40

7. The Correct Response for the Rats in Group 1 .... 4 I

8. The Correct Response for the Rats in Group 2 . . . 42

Schedule

I. Schedule for Group Number I. .......... 43

II. Schedule for Group Number II .......... 4 . . 
CHAPTER I

INTRODUCTION

The purpose of this experiment is to investigate the relationships between "place" or "response" behavior of white rats and tro other variables, their periormance in a reasoning situation and speed of learning a maze habit. It is possible that animals which exhibit "place" behavior perform more efficiently on the reasoning tasks and learn more rapidly than the "response" learners. This does not imply a causal relationship in either direction but it is a beginning attempt to solve the apparent contradictions found in the literature on these topics. As a first step in the study of these relationships it will be necessary to investigate the consistency of the "place" or "response" behavior of these animals. If this is found to be inconsistent no consistent relationships with other phenomena are possible.

The question of what is learned, $i$. e., does the animal exhibit "place" or "response" behavior, is usually investigated through the use of a cross-maze (Figure 1) or the rotation of a T-maze. In the cross-maze the animal is first trained to make a right turn at the choice point, that is to mun from $S_{1}$ to $F_{1}$. He is then placed on the maze at $S_{2}$. If the animal then makes the same, right turn, at 
the choice point, goes from $S_{2}$ to $F_{2}$, this is designated "response" behavior. If, on the test trial, the animal goes to the same location, makes a left turn and goes from $S_{2}$ to $F_{1}$, this is designated "place" behavior.

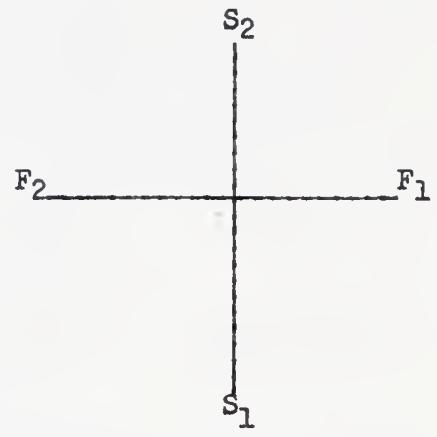

Figure 1.-Cross-maze

\section{Related Iiterature}

An extensive survey of the literature failed to find any experimentation on the consistency of what is leamed by each animal. The work done can be divided into three general areas. The first group of experiments are those which have attempted to determine whether rats learn "responses" or "places" $(8,21,27,28)$. The results of these studies are conflicting and suggest that the animals learn both. The second general area of experimentation was an attempt to determine which of the two, "place" or "response" learning, was the faster, easier $(1,3,6,7,11,24,25,30,31,34,35)$. The results of these experiments are not clear cut and this problem remains unanswered. The third group of studies are those which have attempted 
to determine the various factors involved in "place" or "response" learning $(14,22,23,36)$. These studies have indicated that "place" learning is partially dependent upon such things as number of reinforcements, the abundanco, and availability of various stimuli. This research appears to cast doubt upon the idea that rats are either "place" or "response" learners.

Restle (20) states that the place vs. response issue has been incorrectly formulated. He says, "The details of the single-unit I-maze experiments quite clearly indicate that there is nothing in the nature of the rat which makes it a place or response learner." He asserts that the animals use all of the available cues when learning a maze habit. These cues are extra-maze, intra-maze, or kinesthetic in nature. In the typical "place" vs. "response" experiment the animal is tested in a situation in which he must either go to the same location as on the learning trials (place leaming), or he must make the same movements (response learning). In this type of experiment the various cues mentioned by Restle are put in direct opposition and the animal must respond to one set at the expense of the other. The extramaze cues are those stimuli which are external to the maze, e. g., a stationary light in the room. If these cues are the dominant stimuli for an animal he will exhibit "place" behavior on the test trial. If the cues arising from the movement of the animal, the kinesthetic cues, are dominant, we expect "response" behavior on the test trial. The intra-maze cues are those stimuli, e. g•, olfactory, auditory and 
visual, within the maze. These cues can contribute to either "place" or "response" behavior. In a cross-maze the intra-maze cues direct the animal to the same location. However, if a T-maze is leamed and then rotated for the test trial these cues contribute to "response" behavior. These cues direct him along the same arm of the maze as in the learning trials but this arm now mus to the opposite location. In the above context, the terms "place" and "response" mean: What cues do the animal utilize on the test trial? We infer from the behavior on this test trial which stimuli were dominant in the leaming of the maze habit.

From the evidence, it appears conceivable, as Restle says, that there is nothing in the nature of the organism which makes it either an "absolute place" or "absolute response" learner, that rats cannot be dichotomized into those that utilize only one type of cue as opposed to those that use only another. Howrever, it must be pointed out that when rats are put on a cross-maze at $S_{\mathcal{I}}$ and trained to run to $F_{1}$ for food and then are tested by being placed at $S_{2}$, some rats go to $F_{2}$ and some go to $F_{1}$. Their behavior is different in what appears to be the same situation. What accounts for this difference in behavior?

All of the studies in this area have dealt with rats as a group. They have found, for instance, that the proportion of "place" leamers depends, at least in part, on the extent of extra-maze cues. None of the studies has explored the consistency of the behavior of a 
given animal. We may discover that each animal is relatively consistent in what he learns. This means that in learning a maze habit, any one animal will use all of the available cues but that some may utilize predominantly one type of cue and others may use a different kind. The animal which is a "response" learner with a maximum of extra-maze cues may be a "response" learner with a minimum of extra-maze cues. It is possible that the animals fall on a continuum ranging from those which depend largely on kinesthetic cues to those which utilize primarily the cues outside the organism. Thus, the animals may fall on a curve of a normal distribution rather than into a "place-response" dichotomy.

The primary cues utilized by an animal in a learning situation may be related to his reasoning behavior. A survey of the literature has also failed to bring to light any research on the relationship of "place" or "response" behavior and reasoning. It is necessary to report some of the work done on reasoning, as the results have been conflicting.

In 1929, Maier (17) published an extensive study on reasoning in the white rat. He defined reasoning as, "The ability to bring together spontaneously two elements of past experience without having them previously associated by contiguity." Maier believed, on the basis of his results, that such reasoning does occur in the rat. However, Wolfe and Spragg (37) claimed that the behavior of llaier's animals could be explained without recourse to the concept of reasoning. They repeated three of Maler's experiments, in addition to one problem of 
their own design, and failed to confirm his results. In 1935, Maier defended reasoning in rats in a reply to this criticism. He claimed that they had not replicated his original work and hence had overlooked certain relevant factors. Hull (12) also denies reasoning in rats and attempts to explain Maier's results in stimulus-response terms. Shepard ${ }^{I}$ (19), using a fifteen choice-point maze in which a short-cut could be taken once the maze was learned, also found behavior in rats which he believed to be reasoning. He further found that this reasoning ability was unrelated to learning ability and interpreted this to mean that learning and reasoning are qualitatively different.

The results of these experiments are thus ambiguous and the issue remains unsolved. It is not the purpose of this experiment to detemnine whether reasoning does occur in the white rat. This must be done by other experimentation. However, the detour behavior shown in these situations will be called reasoning.

No studies have been discovered in the literature on the relationship between the speed of leaming a maze habit and what is leamed. If a relationship is found, it may throw light on the differences in the behavior of the animals in what appears to be the same situation. Once again a causal relationship cannot be implied. This study undertakes to investigate the following problems:

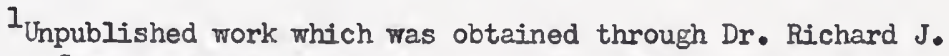
Anderson. Some coverage of this is included in Maier and Schneirla (19). 
1. Does the white rat exhibit consistency in what is learned? This can be further divided into the animals' consistency in the same and different situations.

2. What is the relationship between what is learned and reasoning behavior?

3. What is the relationship between what is learned and speed of learning a maze habit? 


\section{CHAPTER II}

\section{EXPERIMENTAL DESIGN}

As stated previously the purpose of this study is to determine first the consistency of what is learned and then the relationships between what is leamed, reasoning, and speed of learning.

\section{Subjects}

The subjects in this study were 43 naive, albino rats. They were maintained on Purina laboratory chow and water ad libitum. They were housed in the colony room of the Comparative Psychology Laboratory at the University of Florida. These animals were between 65 and 75 days of age at the beginning of the experinent.

The animals were run in tro groups. Group I, consisting of 21 male animals (numbered 1-2I), was received from Rockland Farms on August 29, 1957 and completed training on November 18, 1957. Originally, there were 26 animals; however, two died and three refused to min the maze. Group II, consisting of 22 female animals (numbered 2243), was received from Carsworth Farms on January 11, 1958 and completed training on April 1, 1958. Originally, this group consisted of 26 animals but one died and three refused to mun the maze. The two groups were treated identically insofar as was possible. Any changes in schedule can be seen by comparing Schedules 1 and 2 in the appendix. 


\section{$-9-$ \\ Procedure}

All training and testing of the animals was done between $9: 30$ a. $\mathrm{m}$. and $L: 30 \mathrm{p} . \mathrm{m}$. For the first ten days the animals were tamed by being handled, taught to run a straight elevated runway, and to eat the moist food in pellet form. This taming took place in Room 2, shown in Figures 5 and 6. After the taming, each animal was mun on six tasks in the following order:

Task 1: An elevated cross-maze (Figure 2 in the appendix)

Task 2: An elevated pi-maze (Figure 3 in the appendix)

Task 3: A tunnel crossmaze (Figure 4 in the appendix)

Task 4: A reasoning test (Figure 5 in the appendix)

Task 5: A nine-choice-point tunnel-maze with a detour (Flgure 6 in the appendix)

Task 6: The rats were again mun through Task 1. The rats were motivated by 20-22 hours of food deprivation. The reward on all trials was a moist food pellet, about the size of a large pea, located in a small glass coaster. The antmals were fed ad Iibitum for one hour a day, feeding being started approximately onehalf to one and one-half hours after completion of the day's trials. The exceptions to this feeding schedule are noted below and in Schedules 1. and 2. The anjmals were carried to and from the experimental room in a cage. The elevated maze pathways were fourteen inches high and two inches wide, and the tunnel maze pathways were three inches wide and four and one-half inches high and had the top covered with 
one-half inch wire mesh.

Task 1.--The rats were run on Maze $I$ in Room 1 , as is show in Figure 2. The illumination in this room was in all cases the natural light furnished by the three windows shom in this diagram. The noncorrection method was used and a block was placed just beyond the choice point forcing the animal to make a turn and preventing him from going straight ahead. The animals were run alternately with four or five animals. In other words, each animal ran either every fourth or fifth trial. All of the animals were placed on the maze at $S_{1}$. One-half of the animals was trained to go to $F_{1}$ and the other half was trained to go to $\mathrm{F}_{2}$. Each animal was run seven trials per day with the criterion of learning being five successive correct trials. In case an animal reached the criterion on the seventh trial he was tested the same day.

When the criterion was reached the block was placed on the opposite side of the choice point and the animal was placed at $S_{2}$ for one trial. The number of trials to criterion and the turn taken on the test trial at the choice point were recorded. On Tasks 1, 2, and 3 the animal was never rewarded on the test trial.

Task 2.-Seven days after the last animal completed Task 1 they were started on Task 2 (Figure 3). The feeding schedule for this period is shown in Schedules $I$ and 2. Once again each animal was run every fourth or fifth trial and the non-correction method was used. One-half of the rats was trained to run from $S_{1}$ to $F_{2}$ and the other 
half was trained to run from $S_{2}$ to $F_{2}$. See Figures 7 and 8 for the correct choice for each animal. They were run seven trials per day with a criterion of five, successive, correct trials. When the criterion was reached the animal was tested by being placed on the maze at the $S$ other than the one he had been trained on. In other words, if they had been trained to run from $S_{1}$ to $F_{2}$ they were placed on the maze at $\mathrm{S}_{2}$. If the animal ran to $\mathrm{F}_{2}$ he was classified a "place" leamer. If he ran to either $F_{1}$ or $F_{3}$ he was considered a "response" leamer. Task 3.-Seven days after Task 2 was completed the animals were started on Task 3 (Figure 4). The feeding schedule for these days is shown in Schedules 1 and 2. The procedure for this task was identical with the procedure for Task 1 with the exception, that the correct choice was counter-balanced, as shown in Figures 7 and 8 . Task 4.-After the completion of Task 3 the rats were kept on one hour a day feeding for approximately three days and then started the reasoning test in room 2 (Figure 5). This room had one window with the venetian blinds closed and light was fumished by four overhead 40 watt fluorescent bulbs.

For trelve consecutive days each animal was placed on the apparatus, on $\mathrm{T}$, for ten minutes a day. The portion of the maze represented by the dotted lines and the screen barrier were not in place so the animal could not go from $b$ to $F$ by this route. The barrier between $F$ and $A$ was not in place.

On the thirteenth day the animal was again placed on $T$ for 
one minute. He was then removed for two minutes and the portion of the apparatus represented by the dotted lines in addition to the screen barrier were put in place as show in the diagram. The animal was then run one trial from $b$ to $F$ and fed a food pellet. He was then placed on $\mathrm{N}$, not allowed to move toward $\mathrm{n}$, and run four more trials to food at $F$. Retracing and movement toward $n$ were prevented by the experimenter's hand. The animal was then taken off the apparatus for one minute. Then he was placed on $T$ at $A$ so that the food was in view but inaccessible. Four scores were used as measures of reasoning:

1. the time elapsed between the rat being placed at $A$ and his reaching $b$ on the mun to the food,

2. the number of blind alleys ( $X, Y$ and $Z$ ) taken by the animal before he solved the problem,

3. the time elapsed before the animal began looking for a detour route around the screen, i. e., left area A,

4. the time before the animal first left table $\mathrm{T}$. This apparatus and procedure is a modification of Maier's work on reasoning (1.7).

Task 5. - The next task was the nine-choice-point tunnel maze (Figure 6). This maze was started five days after the completion of the reasoning task. Each animal was given five trials per day and criterion was two successive errorless trials. Once again four or five animals were run alternately. Backtracking was prevented by placing a door in the maze if an animal started to retrace. While 
the animal was leaming the maze the door at the end of blind alley number $I$ was in place. Due to the angle of the maze the animal was unable to see whether this door was open or closed from the first choice point. After the animal reached the criterion this door at the end of blind alley number $I$ was opened and the animal was again placed in the maze at the start. Reasoning was measured by the number of trials until this short cut was taken.

Task 6.-The animals were then put on full diet for three days and then one-hour a day feeding for three more days. They were then mun again on Task 1, following the same procedure as formerly. The anly change in procedure was the correct turn at the choice point. This change is show in Figures 7 and 8. 
CHAPTER III

\section{RESULTS}

In reporting the results a comparison of Group I (males) and Group II (females) will be presented first. This will be followed by the data on each task and then the relationships of these tasks.

\section{Comparison of Group I and Group II}

Of the comparisons made between these two groups only three significant differences were obtained. Two of these differences showed faster learning by the females and one difference indicated the males faster. No significant differences between these groups were obtained on the reasoning measures or "place" vs. "response" measures.

These groups differ in sex, strain and time of muning. No effort will be made to explain the obtained differences. Nuch experimentation $(5,15,16,32,33)$ has been done in an attempt to determine the leaming efficiency of males as compared to females. It has produced conflicting results.

In general the groups perfornances were similar and the results for these two groups have been pooled in this study.

Tasks 1, 2, 3, and 6. - On these tasks (see Figures 2, 3, 
and 4) each animal was trained on a one-choice-point maze and was then tested to deternine whether he exhibited "place" or "response" behavior. The mean number of trials to criterion and sigma for all the animals are presented in Table 1.

TABLE 1

MEAN NUMBER OF TRIALS TO CRITERION ON

TASKS 1, 2, 3, AND 6

\begin{tabular}{|c|c|c|}
\hline Task 1 & $\begin{array}{l}\mathbb{N} \\
\mathbb{M} \\
\sigma\end{array}$ & $\begin{array}{l}43 \\
9.93 \\
4.0\end{array}$ \\
\hline Task 2 & $\begin{array}{l}\frac{N}{\mathbb{M}} \\
\sigma\end{array}$ & $\begin{array}{c}43 \\
8.11_{4} \\
3.8\end{array}$ \\
\hline Task 3 & $\begin{array}{l}\mathbb{N} \\
\mathbb{M} \\
\sigma\end{array}$ & $\begin{array}{l}43 \\
9.79 \\
4.6\end{array}$ \\
\hline Task 6 & $\begin{array}{l}\mathbb{N} \\
\mathbb{N} \\
\sigma\end{array}$ & $\begin{array}{l}43 \\
9.5 \\
5.9\end{array}$ \\
\hline
\end{tabular}

A comparison of the "place" vs. "response" learners on mean number of trials to criterion on Tasks 1, 2, 3, and 6 is presented in Table 2.

None of the $\underline{t}$ ratios of the differences between "place" and "respanse" leamers on mean numbers of trials to criterion is significant at the 5\% level of confidence. This fails to support the hpothesis that speed of learning a maze is related to what is leamed on that maze. 
TABLE 2

A COMPARISON OF PIACE VS. RESPONSE LEARTERS ON MEAN NUMBER OF TRIALS TO CRITERION ON TASKS 1, 2, 3, AND 6

\begin{tabular}{|c|c|c|c|c|}
\hline & Place & Learners & Response Ieamers & t ratio \\
\hline Task 1 & $\begin{array}{l}\mathrm{N} \\
\mathrm{M} \\
\sigma\end{array}$ & $\begin{array}{l}21 \\
10.6 \\
4.0\end{array}$ & $\begin{array}{l}22 \\
9.3 \\
3.6\end{array}$ & 1.08 \\
\hline Task 2 & $\begin{array}{l}\mathbb{N} \\
\mathbb{M} \\
\sigma\end{array}$ & $\begin{array}{l}12 \\
10.0 \\
4.0\end{array}$ & $\begin{array}{l}31 \\
7.4 \\
3.6\end{array}$ & 1.95 \\
\hline Task 3 & $\begin{array}{l}\mathrm{N} \\
\mathbb{M} \\
\sigma\end{array}$ & $\begin{array}{l}21 \\
8.5 \\
4.7\end{array}$ & $\begin{array}{l}22 \\
11.0 \\
4.2\end{array}$ & 1.82 \\
\hline Task 6 & $\begin{array}{l}\mathbb{N} \\
\mathbb{N} \\
\sigma\end{array}$ & $\begin{array}{l}22 \\
8.5 \\
3.7\end{array}$ & $\begin{array}{l}21 \\
10.6 \\
7.2\end{array}$ & 1.17 \\
\hline
\end{tabular}

Task 4.--This task makes use of a modification of Maier's (17) reasoning apparatus show in Figure 5. Of the 43 animals run on this apparatus, 1 failed to reach the food on the test trial, within the allotted time of 420 seconds. The remaining 32 animals took the route from $b$ to $F$, within this time limit. As stated previously, four measures of reasoning were used:

1. tine required by the aninal to reach $b$ on the mun to $F$,

2. the number of blind alleys taken by the animal,

3. tine elapsed until the animal first left area $\mathbb{A}$ on the apparatus,

4. time elapsed until the animal first left table $T$ on the apparatus. 


$$
-17-
$$

The intercorrelations for these measures of reasoning are presented in Table 3.

\section{TABLE 3}

RELATIONS OF REASONING IEASURES ON TASK 4

\begin{tabular}{cc} 
Weasures of Reasoning & $\begin{array}{c}\text { Pearson } \\
\text { Correlation Coefficient }\end{array}$ \\
\hline I and II & .4 .7 \\
I and III & .25 \\
I and IV & .26 \\
II and III & -.08 \\
II and IV & .16 \\
III and IV & .76
\end{tabular}

Heasures III and IV are not independent. Often when the animaI left area $A$ he also immediately left the table $T$. These low intercorrelations seer to cast doubt on the assumption that all of these indices measure the same thing, i. e., reasoning. It is possible that reasoning is not unitary. This writer believes Neasure I to be the most valid index of reasoning as this indicates the length of time required by the animal to achieve his goal by use of the detour route. The mean scores of each measure for the animals that reasoned on Task 4 (went from $b$ to $F$ on the test trial) are presented in Tablo 4. The mean scores of each measure for the animals that did not reason (did not go from $b$ to $F$ on the test trial) are shown in Table 5 . 
It must be pointed out that seven of the 11 animals that did not reason seemed to "give up" before the allotted time had elapsed. These animals turned their backs on the food and sat, washed, and appeared to sleep.

TABLE 4

MEAN MEASURES FOR THE ANTMAIS THAT REASONED ON TASK 4

\begin{tabular}{ccccc}
\hline & \multicolumn{4}{c}{ Reasoning Measures } \\
\cline { 2 - 5 } $\mathbb{M}^{4}$ & $135.3^{\prime \prime}$ & 2.2 alleys & $18.2^{\prime \prime}$ & $42.1^{\prime \prime}$ \\
\multirow{2}{*}{$\sigma$} & 108.3 & 1.8 & 21.2 & 39.8 \\
\hline
\end{tabular}

TABIE 5

IEAN MEASURES FOR THE ANTMAIS THAT DID NOT REASON ON TASK 4

\begin{tabular}{|c|c|c|c|}
\hline \multicolumn{4}{|c|}{ Reasoning Mieasures } \\
\hline & II & III & IV \\
\hline M & 1.8 alleys & $75.9^{\prime \prime}$ & $91.6 " 1$ \\
\hline$\sigma$ & 2.2 & 98 & 118.0 \\
\hline
\end{tabular}

The $t$ ratios for the differences between the reasoners and nonreasoners on mean scores for Keasures II, III, and IV are presented in Table 6. No $\underline{t}$ is indicated for Measure $I$ as the non-reasoners did not reach point $F$.

None of the $t$ ratios between the differences of reasoners and non-reasoners on mean scores of Measures II, III, and IV is significant 
at the $5 \%$ level of confidence. These results further suggest that Measure I is unrelated to Measures II, III, and IV on Task 4.

TABLE 6

A COMPARISON OF REASONERS AND NON-REASONERS ON THE NEASURES ON TASK 4

$\begin{array}{cc}\text { Reasoning Measures } & \text { t ratio } \\ \text { II } & .40 \\ \text { III } & 1.4 .44 \\ \text { IV } & 1.38\end{array}$

Task 5.-This task makes use of the nine-choice-point tunnel maze with a detour route (Figuro 6). Forty-three animals were started on this maze; however, one refused to run and one animal was terminated at the end of sixty trials when he had not reached learning criterion. One additional animal was terminated when he had failed to reason after 37 reasoning trials. Forty-one animals learned this maze and 40 exhibited reasoning, $i$. e., took the detour route. The mean and sigma for number of trials to learning criterion and number of trials to reasoning are presented in Tablo 7.

The correlation, $r=+.33$, between number of trials to learning criterion and number of trials to reasoning by use of the detour route, is significantly different from $r=.00$ at the $5 \%$ level of confidence. This correlation indicates a positive relationship between speed of 
leaming and speed of reasoning as measured by this maze.

\section{TABIE 7}

DATA ON MEAN NULBER OF TRIAIS TO LEARNING CRITERION AND MEAN NUMBER OF TRIAIS TO REASONING ON TASK 5

\begin{tabular}{ccc}
\hline & $\begin{array}{c}\text { Trials to } \\
\text { Learning Criterion }\end{array}$ & $\begin{array}{c}\text { Trials to } \\
\text { Reasoning }\end{array}$ \\
\hline$N$ & 41 & 40 \\
$N$ & 21.9 & 6.2 \\
$\sigma$ & 9.4 & 6.8 \\
\hline
\end{tabular}

We now turn to the relationships between the various tasks and investigate the three problems presented in Chapter I.

\section{Consistency of What is Learned}

Task 1 and Task 6.- On a comparison of what is learned on Tasks 1 and 6, we find that 16 of the animals were consistent, i. e., exhibited the same type of behavior on the test trial of both mazes. of the consistent animals, 8, or 50\%, showed "place" behavior in both situations. On a chance basis we would expect 50\% (21.5) of the 43 animals to be consistent. $A X^{2}=2.82$, with 1 degree of freedom, between the obtained and expected frequencies of consistent and inconsistent animals is not significant at the $5 \%$ level of confidence. Notice should be taken that the majority of the animals were inconsistent. These results suggest that the "place" or "response" behavior of the individual animal may not be consistent over time in the same 
situation.

Task 1, Task 2, and Task 3.-A comparison of the kind of behavior, "place" or "response," of each animal on Tasks 1, 2, and 3 yields further information on the consistency of what is learned. In presenting these data the following designations are used:

1. $3 \mathrm{R}-$ - is used to indicate the anjmals that exhibited resporse behavior on the test trials of all three mazes.

2. $2 R-I P$ - is used to indicate the animals that exhibited response behavior on two of the mazes and place behavior on one maze.

3. I $R-2 P-$ is used to indicate the animals that exhibited place behavior on two of the mazes and response behavior on one maze.

4. $3 \mathrm{P}-$ is used to indicate the animals that exhibited place behavior on all three mazes.

The number of animals in each of the "place-response" categories and the number that would be expected in each by chance is shown in Table 8.

The chi-square $\left(x^{2}=3.45\right.$, with 2 degrees of freedom $)$ between the obtained and expected frequencies in these "place-response" categories is not significant at the 5\% level of confidence. This fails to support the hypothesis that anjmals are either "place" or "response" learners and suggests that animals fall on a normal distribution rather than into a dichotomer. 
TABLE 8

TYPE OF BEHAVIOR EXHIBITED ON THE TEST TRIALS OF TASKS 1, 2, AND 3

\begin{tabular}{lccccc}
\hline & \multicolumn{5}{c}{ Place-Response Category } \\
\cline { 2 - 5 } & $3 \mathrm{R}$ & $2 \mathrm{R}-1 \mathrm{P}$ & $\mathrm{I} \mathrm{R}-2 \mathrm{P}$ & $3 \mathrm{P}$ \\
\hline \multirow{2}{*}{ Expected $N$} & 8 & 19 & 13 & 3 \\
& 5.4 & 16.2 & 16.2 & 5.4 \\
\hline
\end{tabular}

Comparison of Reasoning Ability as Measured on Task 4 and Task 5

As stated previously, on Task 4,32 of the animals exhibited reasoning behavior. On Task 5, 40 of the 47 animals that leamed this maze exhibited reasoning behavior.

The correlation, $r=+.01$, between reasoning on Task 5 and Measure I of reasoning on Task 4 is not significantly different from $r=.00$. This low correlation casts doubt upon the assumption that these tasks, or at least the criteria used, both measure the same thing.

\section{Relationship of What is Learmed and Reasoning Ability}

Tasks 1, 2, 3, and Task 4. - The information show in Table 9 indicates the number of animals in each "place-response" category that reasoned on Task 4, and the number that would be expected to reason by chance.

As the expected frequency for animals in the $3 \mathrm{P}$ category is less than 5, the categories have been combined to include those that are 
predominantly "response" leamers as opposed to those that are predominantly "place" leamers. These results are presented in Table 10.

TABLE 9

NUIBER OF ANTMALS REASONING ON TASK BY PLACE-RESPONSE CATEGORY ON TASKS 1, 2, AND 3

\begin{tabular}{lllll}
\hline & \multicolumn{4}{c}{ Place-Response Category } \\
\cline { 2 - 5 } N R & 2 R-1 P & I R-2 P & 3 P \\
\hline \multirow{2}{*}{ Number Reasoning } & 3 & 19 & 13 & 3 \\
Expected Reasoning & 6 & 14 & 13 & 2 \\
& & 14.25 & 9.5 & 2.25 \\
\hline
\end{tabular}

TABLE 10

NURBER OF ANTMALS REASONING BY PREDOUTIVANT "PIACE" OR "RESPONSE" BEHAVIOR ON TASKS 1, 2, AND 3

\begin{tabular}{lcc}
\hline & $\begin{array}{c}\text { Predominantly } \\
\text { Response }\end{array}$ & $\begin{array}{c}\text { Predominantly } \\
\text { Place }\end{array}$ \\
\hline N & 27 & 16 \\
Number Reasoning & 17 & 15 \\
Expected Reasming & 20.1 & 11.9 \\
\hline
\end{tabular}

The chi-square $\left(x^{2}=1.29\right.$, with 1 degree of freedom $)$ between expected and obtained frequencies in the "place-response" categories is not significant at the $5 \%$ level of confidence. This datum fails to support the hypothesis that what is learned on Tasks 1, 2, and 3 is related to whether or not an animal reasons on Task 4. 


$$
-24-
$$

Table 11 presents the data comparing the mean scores for the four measures of reasoning on Task 4 , for the 32 animals reasoning, with their "place-response" category on Tasks 1, 2, and 3.

\section{TABLE 17}

COMPARISON OF MEAN REASONING LEASURES ON TASK 4 AND PIACE-RESPONSE CATEGORY ON TASKS 1, 2, AND 3

\begin{tabular}{|c|c|c|c|c|c|}
\hline & \multicolumn{4}{|c|}{ Place-Response Category } & ratio \\
\hline $\mathbb{N}$ & 8 & 19 & 14 & 3 & \\
\hline \multicolumn{6}{|c|}{$\begin{array}{l}\text { Reasoning } \\
\text { Measure }\end{array}$} \\
\hline I & $102^{\prime \prime}$ & 143.611 & $142.9 "$ & $93.5^{\prime \prime}$ & .23 \\
\hline II & 2.3 alleys & 2.5 alleys & 1.85 alleys & 1.5 alleys & .35 \\
\hline III & $16.7^{\prime \prime}$ & $10.5^{\prime \prime}$ & 27.3 & $22^{\prime \prime}$ & 1.28 \\
\hline IV & $59^{\prime \prime}$ & $32.7 "$ & $49.2^{\prime \prime}$ & $36.5^{\prime \prime}$ & .57 \\
\hline
\end{tabular}

None of the $F$ ratios involving mean reasoning scores by "place-response" category is significant at the 5\% level of confidence. These data do not support the hypothesis, for those animals that reason, that reasoning, as measured by these criteria, is related to what is learned on Tasks 1,2 , and 3.

Tasks $1,2,3$, and Task 5. -The relationship between what is learned on Tasks 1,2 , and 3 and the reasoning behavior on Task 5 is presented in Table 12. 
TABIE 12

MEAN NULABER OF TRIAIS TO REASONIIG ON TASK 5 BY

PLACE-RESPONSE CATEGORY ON TASKS 1, 2, AND 3

\begin{tabular}{|c|c|c|c|c|c|}
\hline & \multicolumn{4}{|c|}{ Place-Response Category } & $\underline{F}$ ratio \\
\hline $\mathrm{N}$ & 7 & 18 & 12 & 3 & \\
\hline $\mathbb{M}$ & 8.0 & 5.5 & 6.7 & 1.3 & 1.00 \\
\hline$\sigma$ & 9.4 & $4 \cdot 3$ & 7.1 & .54 & \\
\hline
\end{tabular}

The F ratio involving the mean reasoning score by "place-response" category is not significant at the 5\% level of confidence, and fails to support the hypothesis that what is leamed is related to reasoning efficiency as measured on Task 5 .

Relation of What is Learned and Spoed of Learning Tasks 1, 2, and 3.- - It was previously stated that no relationship was found between the number of trials to criterion and "place" or "response" behavior on any individual one-choice-point maze. Table 13 presents data on the mean number of trials to criterion according to the animals "place-response" category on Tasks 1, 2, and 3.

None of the $F$ ratios of the differences of mean number of trials to criterion by "place-response" category is simnificant at the $5 \%$ level of confidence. No relationships are obtained between the speed of learming and what is learned.

Table 14 presents the relation of what is learned and the number 
of trials to learning criterion on a complex maze (Task 5).

\section{TABLE 13}

MEAN NUMBER OF TRIAIS TO CRITERION ON TASKS 1, 2, AND 3 BY PLACE-RESPOINSE CATEGORY

\begin{tabular}{|c|c|c|c|c|c|}
\hline & \multicolumn{4}{|c|}{ Place-Response Category } & \multirow[b]{2}{*}{ E ratio } \\
\hline & $3 R$ & $2 R-1 \mathrm{P}$ & $1 \mathrm{R}-2 \mathrm{P}$ & $3 \mathrm{P}$ & \\
\hline $\mathrm{N}$ & 8 & 19 & 13 & 3 & \\
\hline Task I & 7.75 & 9.68 & 11.77 & 9.33 & 1.84 \\
\hline Task 2 & 6.37 & 8.30 & 8.92 & 6.67 & .94 \\
\hline Task 3 & 10.50 & 10.00 & 9.38 & 8.33 & .18 \\
\hline
\end{tabular}

TABLE 14

MEAN NUMBER OF TRIALS TO CRITERION ON TASK 5 by PLACE-RESPONSE CATEGORY ON TASKS 1, 2, AND 3

\begin{tabular}{|c|c|c|c|c|c|}
\hline & \multicolumn{4}{|c|}{ Place-Response Category } & \multirow[b]{2}{*}{ F ratio } \\
\hline & $3 R$ & $2 \mathrm{R}-1 \mathrm{P}$ & $1 \mathrm{R}-2 \mathrm{P}$ & $3 \mathrm{P}$ & \\
\hline $\mathrm{N}$ & 7 & 18 & 23 & 3 & \\
\hline $\mathbb{M}$ & $24 \cdot 1$ & 20.6 & 21.5 & 25 & .36 \\
\hline$\sigma$ & 7.8 & 8.9 & 11.4 & 4.5 & \\
\hline
\end{tabular}

The $F$ ratio of the differences between mean number of trials to leaming criterion on Task 5 by "place-response" category is not significant at the $5 \%$ level of confidence. These results do not verify the hypothesis that speed of learning a complex maze is related to the "place" or "response" behavior of the animals. 
CHAPTER IV

\section{INTERPRETATION AND DISCUSSION}

\section{Consistency of What is Learned}

The results suggest that any individual rat does not show absolute consistency in the kinds of cues that it utilizes when learning a maze. It was stated previously that it is probable that each animal uses all available cues in a learning situation. However, when these cues are made to conflict, some animals appear to utilize the extramaze cues while others appear to utilize the kinesthetic cues. The indications are that the animals can and do utilize various cues in different situations. These findings cast doubt on the assumption that rats fall into a dichotomy of either "place" or "response" learners. In a repeat of the same maze (Tasks 1 and 6) 63\% of the animals were inconsistent on the test trials. This indicates that the animal may not respond to the same cues even in the same situation over time. There were approximately 65 days between the two test trials, so the fact that the animals were not rewarded for their choice on the first test trial is probably unimportant.

From Restle's framework, this indicates that there is nothing within the animal which makes it respond uniquely to either kinesthetic 
cues or to the cues originating outside of the organism.

A further indication that the animals do not fall into a "place-response" dichotomy is found by comparing the behavior of the animals on the test trials of Tasks 1, 2, and 3. The responses, as shown in Table 8, tend to fall in a normal distribution. This could be due to one of two factors:

1. The animals are inconsistent and there is nothing in the organism which makes it tend to be either a "place" or "response" learner. In other words, the behavior of the animals on the test trial is determined by the wealth of extra-maze cues, as has been shown in earlier studies, and chance.

2. The animals are relatively consistent from situation to situation. They range from those animals which are "place" leamers in almost any situation to those that are primarily "response" learners.

The first alternative seems more likely in light of the fact that animals appear to be inconsistent on a repeat of the same situation. These results tend to support Restal's hypothesis that there is nothing in the nature of a rat which makes it a "place" or "response" leamer. Further investigation should be carried out on the question of relative consistency.

One observation should be made at this point. Task 2, the pi maze, produced a relatively small number of "place" learners. This might be due to the fact that on Tasks 1 and 3 the intra-maze cues com- 
bined with the extra-maze cues to direct the animals to the same location. On Task 2 there were no available intra-maze cues. Experimentation should be done to determine the relative importance of the intramaze cues and attempt to determine just what these cues are. This has been done by Walker, Dember and Earl (35) but the intra-maze cues were exaggerated by painting the alleys different colors.

The results discussed therefore are in essential agreement with the ideas presented by Restle (20). It appears that any valid leaming theory must take into account the fact that animals may use varied cues in a learning situation. The classical approach to the "place" vs. "response" controversy, in light of these results, seems to lead us into a blind alley. Further research should attempt to determine the relative importance of the various cues. This can be done by manipulating the cues mentioned previously.

Relation of What is Leamed and Reasoning Ability

Before the relationship between reasoning ability and placeresponse behavior is reported the various criteria of reasoning should be compared.

On Task 4 there were four measures of reasoning used. These measures were adapted from laier's (17) criteria. The intercorrelations between these measures, as presented in Table 3, are rather low. The highest correlation is between measures III and IV, $r=+.76$. It has been pointed out previously that these two measures are not independent. These results cast doubt on the idea that all of these criteria 
measure the same thing. It is possible that reasoning is not unitary and these criteria are measures of different aspects of reasoning.

Further doubt is cast on the validity of these measures by comparing the scores of those animals that reason, obtain food on the test trial, with the scores of the non-reasoners. No significant differences were found between the measures for these two groups. Two tenable explanations to account for these results are:

1. This task does not measure reasoning ability in the white rat.

2. This task can measure whether or not an animal does reason but the criteria are not sufficiently sensitive to measure the efficiency or speed of reasoning.

These results question whether Maier's apparatus really does demonstrate reasoning in the white rat. This does not imply that reasoning does not exist in these anjmals.

The correlation, $r=+.01$, between reasoning on Task 5 and Measure I of reasoning on Task 4 shows that these two tasks are not measuring the same thing.

On Task 5 the correlation, $r=+.33$, between number of trials to learning and number of trials to reasoning is significantly different from $r=.00$ at the $5 \%$ level of confidence. This indicates that the faster leamers tend also to reason faster than the slower leamers. These results are contrary to those obtained by Shepard (19), who found no relationship between speed of learning and speed of reasoning in a similar maze. No relationships were found between speed of learning a 
complex maze and the reasoning measures of Naier's apparatus.

On comparing what is learned and reasoning behavior, we find:

1. no relationship between whether or not an animal reasons on Maier's apparatus and his "place-response" behavior,

2. no relationships between the four measures of reasoning on liaier's apparatus and "place-response" behavior,

3. no relationship between reasoning on the modification of Shepard's maze and "place-response" behavior.

These results all fail to indicate a relationship between what is leamed and reasoning ability as these have been measured. If the animals are inconsistent in their "place-response" behavior these results would be expected. A relationship would suggest that the animals were relatively consistent in the cues that are predominant for them in a learning situation.

Relation between What is Learned and Speed of Learning This topic was investigated in three ways:

1. the relationship between number of trials to criterion in a one-choice-point maze and the behavior of the animal on the test trial of that maze,

2. the relationship between what is learned on three one-choicepoint mazes and number of trials to criterion on each of these mazes, 3. the relationship between what is learned on three one-choicepoint mazes and number of trials to criterion on a nine-choice-point tunnel maze. 
No relationships were found in any of the above conditions. This is not proof, of course, that no relationships exist, but it does suggest that speed of learning is not related to "place-response" behavior. 
CHAPTER V

\section{SURMARY}

The purpose of this study was to determine:

1. Is the "place" or "response" behavior of a white rat consistent?

2. What relationships exist between reasoning and "place" or "response" behavior?

3. What relationships exist between speed of learning a maze habit and "place" or "response" behavior?

This experiment consisted of each of the 43 animals being run on six tasks. Four of these tasks consisted of the rat learning a one-choice-point maze and then being tested for "place" or "response" behavior. Of the two remaining tasks, used to measure reasoning, one was a modification of Maier's (17) technique and the other was adapted from Shepard (19).

\section{The findings:}

1. Indicate that the animals are inconsistent in their "place" or "response" behavior and do not fall into a "place" vs. "response" dichotomy. It is still conceivable that the animals fall on a continuum as to the cues that are predominant in learning a maze habit. 
2. fail to find any relationship between "place" or "response" behavior and reasoning in the white rat, and

3. fail to indicate any relationship between "place" or "response" behavior and speed of learning a maze habit as measured by number of trials to criterion.

It appears that the place vs. response controversy is incorrectly formulated. The results indicate, as Restle (20) suggests, that the animals use all of the available cues in a learning situation. Further study should attempt to identify these cues and determine their relative importance rather than follow the "place-response" experimentation classically carried on in this area.

Doubt is cast upon the assertion that the apparatus modified from Maier (17) measures reasoning. Further research in this area should attempt to ascertain whether reasoning can occur in the white rat. 
APPENDIX 
$-36-$

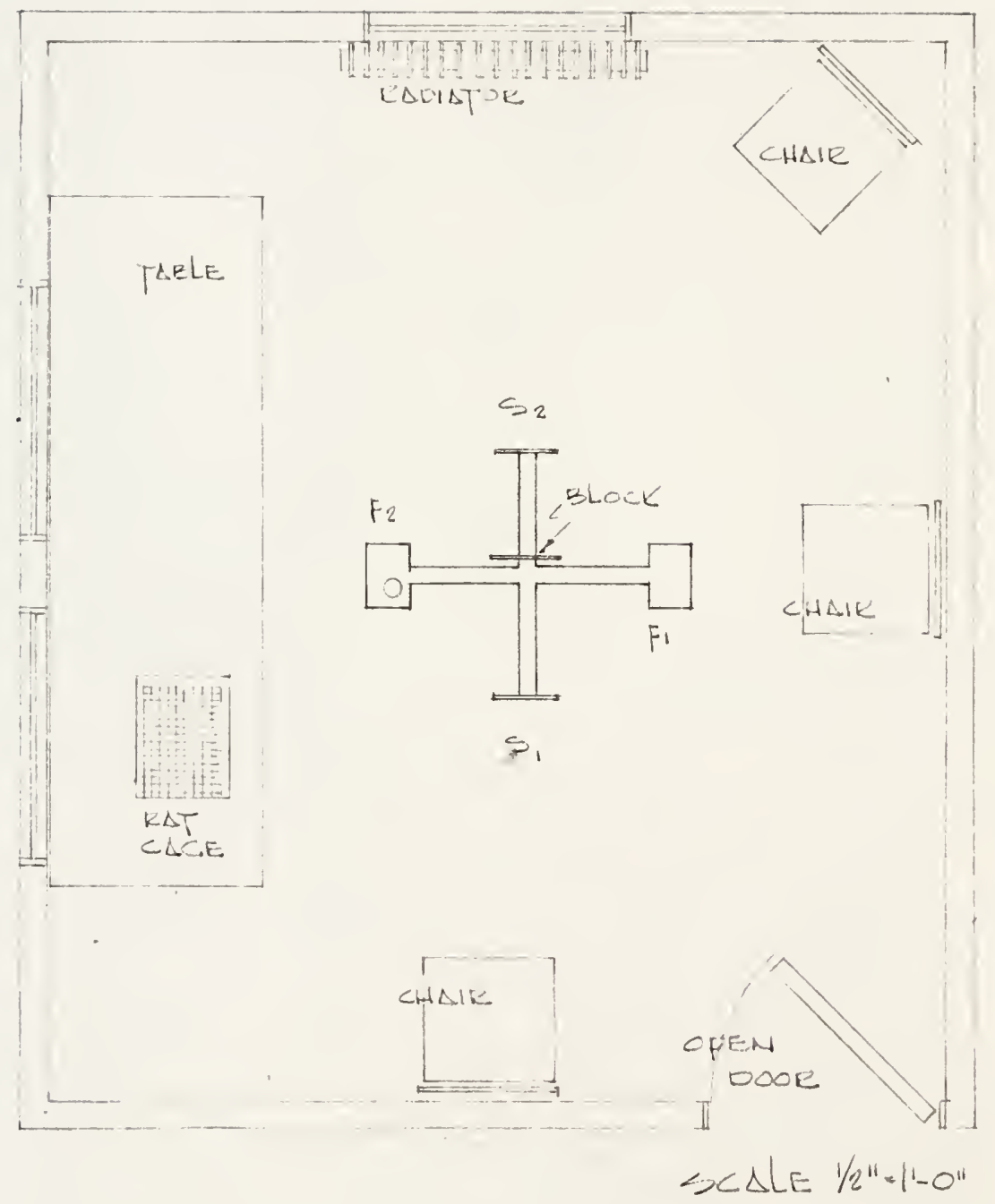

Figure 2.--Diagram of Tasks 1 and 6 in Room 1. 


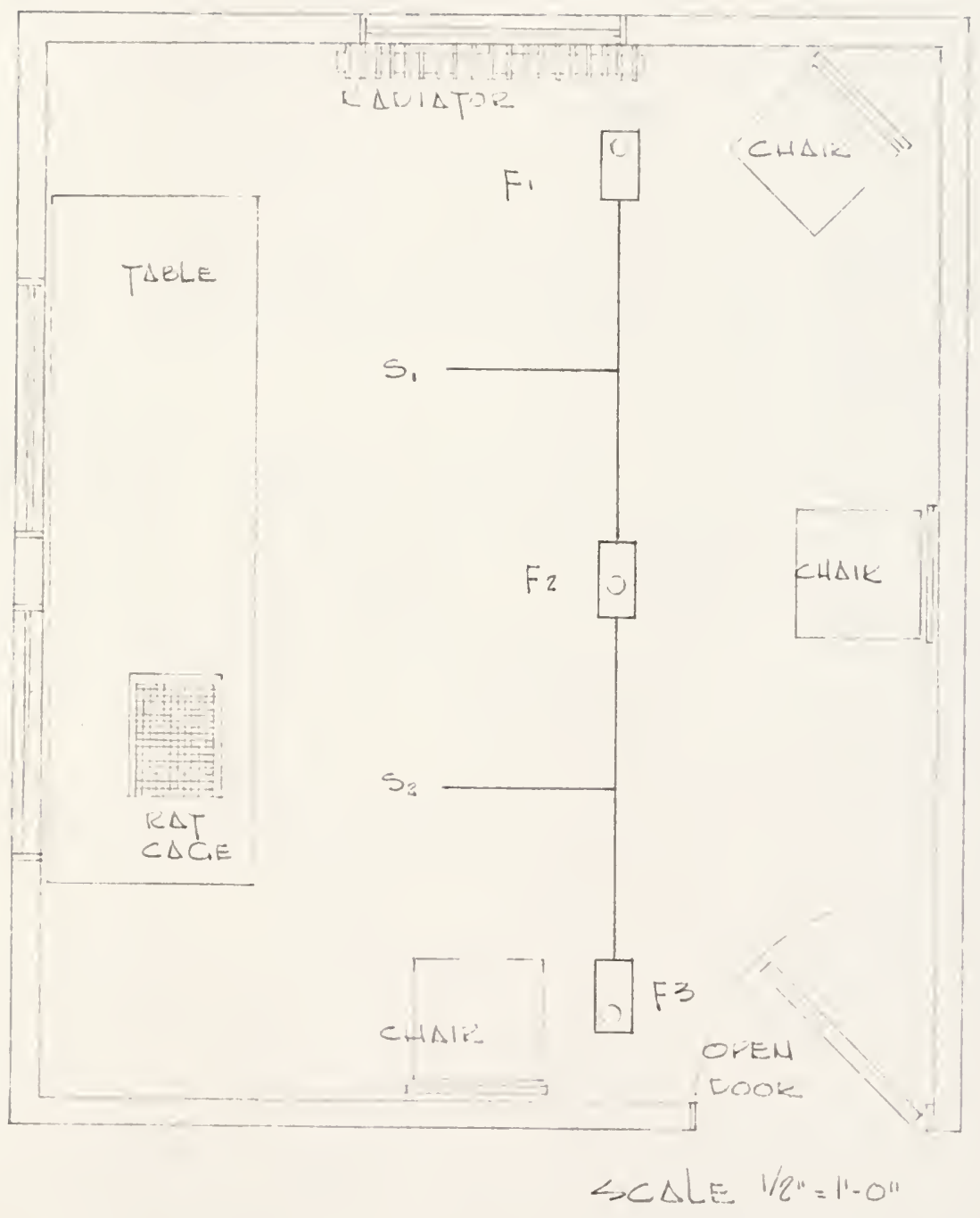

Figure 3.-Diagram of Task 2 in Room 1. 


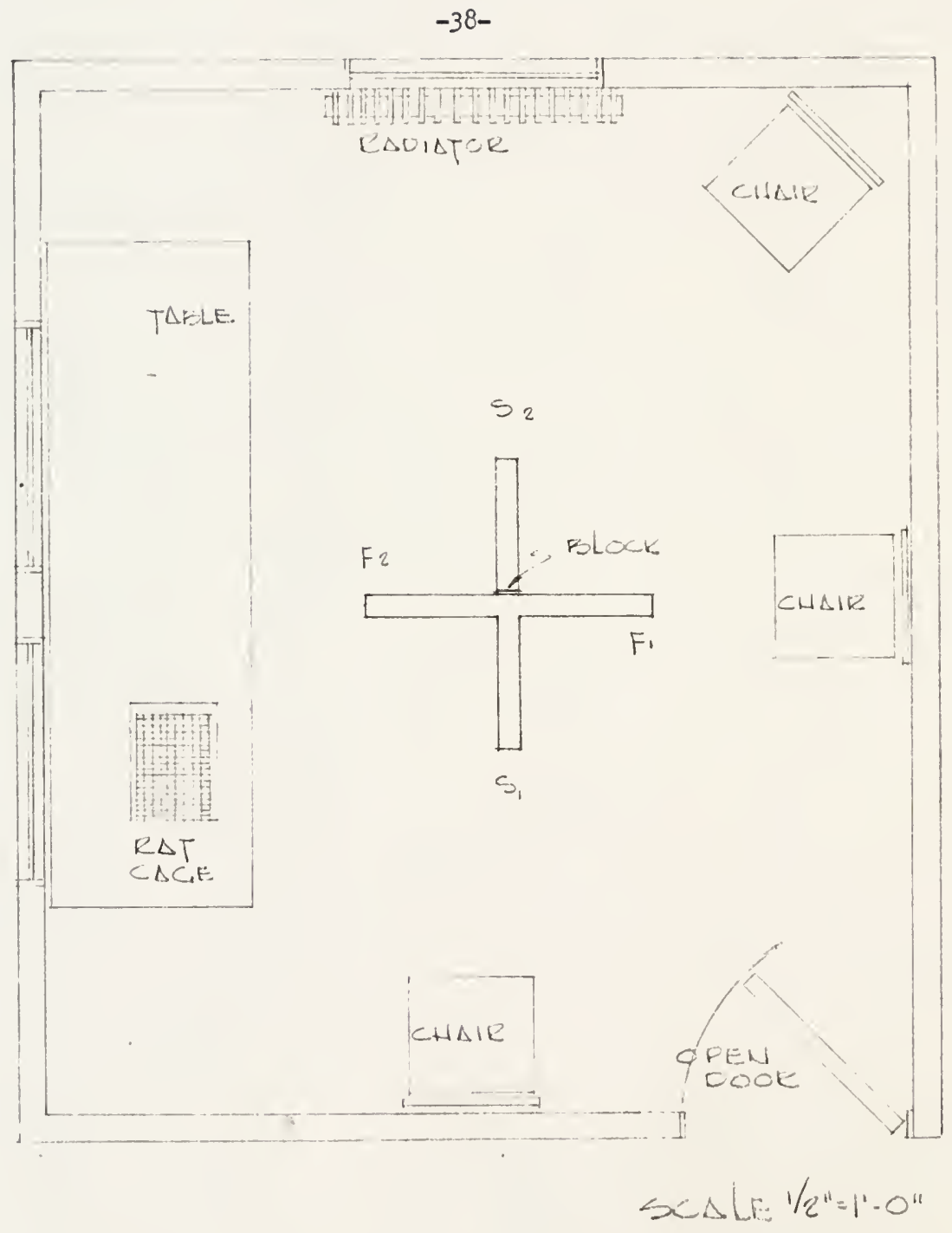

Figure 4.-Diagram of Task 3 in Room 1. 


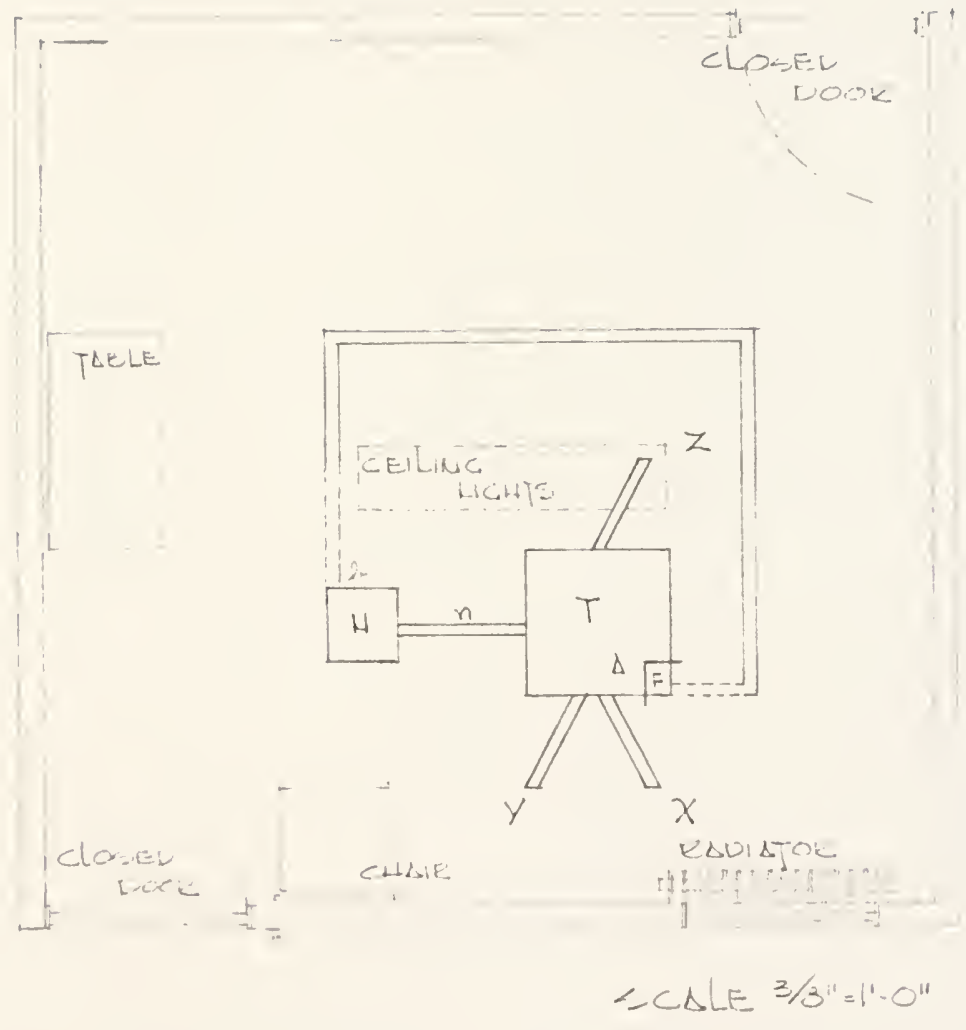

Figure 5.-Diagram of Task 4 in Room 2. 


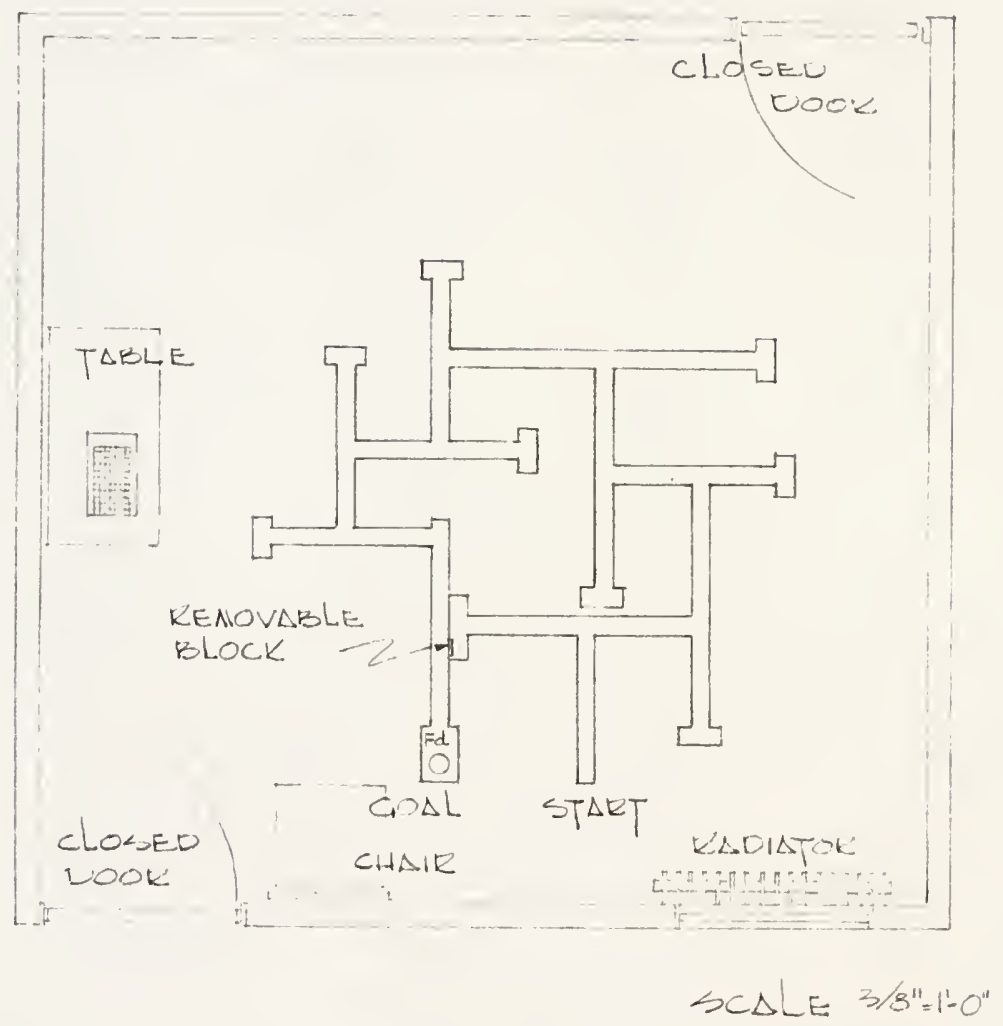

Figure 6.--Diagram of Task 5 in Room 2. 


\begin{tabular}{|c|c|c|c|c|}
\hline \multirow{2}{*}{$\begin{array}{c}\text { Rat } \\
\text { Number }\end{array}$} & \multicolumn{4}{|c|}{ Task } \\
\hline & 1 & 2 & 3 & 6 \\
\hline 1 & $R *$ & $\mathrm{R}$ & $\mathrm{R}$ & $\mathrm{R}$ \\
\hline 2 & $\mathrm{R}$ & $\mathrm{R}$ & $\mathrm{R}$ & $L=-$ \\
\hline 3 & $R$ & $\mathrm{R}$ & $\mathrm{R}$ & $\mathrm{R}$ \\
\hline 4 & $\mathrm{R}$ & $\mathrm{R}$ & $\mathrm{R}$ & I \\
\hline 5 & $R$ & $\mathrm{R}$ & L & $\mathrm{R}$ \\
\hline 6 & $\mathrm{R}$ & $\mathrm{R}$ & I & I \\
\hline 7 & $R$ & $R$ & L & $\mathrm{R}$ \\
\hline 8 & $\mathrm{R}$ & I & L & I \\
\hline 9 & $\mathrm{R}$ & L & L & $R$ \\
\hline 10 & $\mathrm{R}$ & L & $\mathrm{R}$ & L \\
\hline 11 & $\mathrm{R}$ & I & $\mathrm{R}$ & $\mathrm{R}$ \\
\hline 12 & $R$ & $L$ & $\mathrm{R}$ & L \\
\hline 13 & I & L & $\mathrm{R}$ & $\mathrm{R}$ \\
\hline 14 & L & $I$ & $R$ & I \\
\hline 15 & L & L & L & $\mathrm{R}$ \\
\hline 16 & L & $\mathrm{R}$ & L & L \\
\hline 17 & L & $\mathrm{R}$ & L & $\mathrm{R}$ \\
\hline 18 & L & $R$ & $\mathrm{R}$ & I \\
\hline 19 & L & $\mathrm{R}$ & $\mathrm{R}$ & $\mathrm{R}$ \\
\hline 20 & L & I & I & I \\
\hline 21 & L & L & I & $\mathrm{R}$ \\
\hline
\end{tabular}

Figure 7.--The Correct Response for the Rats in Group 1

瓶 $=$ right

$\because * \mathrm{~L}=$ left 
Rat

Number

\begin{tabular}{|c|c|c|c|}
\hline \multicolumn{4}{|c|}{ Task } \\
\hline$\underline{I}$ & 2 & $\underline{3}$ & 6 \\
\hline$R_{* x}$ & $\mathrm{R}$ & $R$ & $\mathrm{R}$ \\
\hline $\mathrm{R}$ & $\mathrm{R}$ & $R$ & $L *$ \\
\hline $\mathrm{R}$ & $\mathrm{R}$ & $\mathrm{R}$ & $\mathrm{R}$ \\
\hline $\mathrm{R}$ & $\mathrm{R}$ & $\mathrm{R}$ & L \\
\hline $\mathrm{R}$ & $\mathrm{R}$ & L & $\vec{R}$ \\
\hline R & $\mathrm{R}$ & $\bar{L}$ & I \\
\hline $\mathrm{R}$ & $\mathrm{R}$ & L & $\mathrm{R}$ \\
\hline $\mathrm{R}$ & $R$ & I & I \\
\hline $\mathrm{R}$ & I & I & $\mathrm{R}$ \\
\hline$R$ & I & L & I \\
\hline $\mathrm{R}$ & I & I & L \\
\hline $\mathrm{R}$ & I & $R$ & $\bar{I}$ \\
\hline $\mathrm{R}$ & I & $\mathrm{R}$ & $\mathrm{R}$ \\
\hline I & I & $\mathrm{R}$ & I \\
\hline L & I & $\mathrm{R}$ & $\mathrm{R}$ \\
\hline L & $R$ & L & L \\
\hline I & $R$ & I & $\bar{I}$ \\
\hline L & $R$ & $\mathrm{R}$ & $\mathrm{R}$ \\
\hline L & $\mathrm{R}$ & $\mathrm{R}$ & I \\
\hline $\bar{I}$ & $\vec{L}$ & L & $\vec{R}$ \\
\hline I & L & L & L \\
\hline I & I & I & $\overline{\mathrm{L}}$ \\
\hline
\end{tabular}

Figure 8.-The Correct Response for the Rats in Group 2

$* \mathrm{R}=$ right

$* \because L=$ left 
SCHEDULE I

Schedule for Group Number I

\begin{tabular}{|c|c|c|}
\hline $\begin{array}{l}\text { Day } \\
\text { Number }\end{array}$ & Date & Schedule \\
\hline 1 & Aug. 29, 1957 & $\begin{array}{l}\text { Animals received-- } \\
55-65 \text { days of age }\end{array}$ \\
\hline $2-11$ & Aug. 30-Sept 8 & Animals tamed \\
\hline $12-14$ & Sept. 9-11 & Run on Task 1 \\
\hline $15-17$ & Sept. $12-14$ & Full feed \\
\hline $18-20$ & Sept. $15-17$ & Fed one hour per day \\
\hline $21-23$ & Sept. $18-20$ & Run on Task 2 \\
\hline $24-26$ & Sept. $21-23$ & Full feed \\
\hline $27-29$ & Sept. $24-26$ & Fed one hour per day \\
\hline $30-32$ & Sept. 27-29 & Run on Task 3 \\
\hline $33-36$ & Sept. 30-0ct. 3 & Fed one hour per day \\
\hline $37-50$ & Oct. $4-17$ & Run on Task 4 \\
\hline $51-55$ & Oct. $18-22$ & Fed one hour per day \\
\hline $56-72$ & Oct. 23-Nov. 8 & Run on Task 5 \\
\hline $73-75$ & Nov. 9-11 & Full feed \\
\hline $76-78$ & Nov. $12-14$ & Fed one hour per day \\
\hline $79-82$ & Nov. $15-18$ & Run again on Task I \\
\hline
\end{tabular}


SCHEDULE II

Schedule for Group Number II

\begin{tabular}{|c|c|c|}
\hline $\begin{array}{l}\text { Day } \\
\text { Number }\end{array}$ & Date & Schedule \\
\hline 1 & Jan. 11, 1958 & $\begin{array}{l}\text { Animals received- } \\
55-65 \text { days of age }\end{array}$ \\
\hline $2-11$ & Jan. $12-2 I$ & Animals tamed \\
\hline $12-14$ & Jan. 22-24 & Run on Task 1 \\
\hline $15-17$ & Jan. 25-27 & Full feed \\
\hline $18-20$ & Jan. 28-30 & Fed one hour per day \\
\hline $21-23$ & Jan. 3l-Feb. 2 & Run on Task 2 \\
\hline $24-26$ & Feb. 3-5 & Full feed \\
\hline $27-29$ & Feb. 6-8 & Fed one hour per day \\
\hline $30-32$ & Feb. 9-1l & Pun on Task 3 \\
\hline $33-36$ & Feb. 12-14 & Fed one hour per day \\
\hline $37-50$ & Feb. $15-28$ & Pun on Task 4 \\
\hline $51-56$ & March 1-6 & Fed one hour per day \\
\hline $57-73$ & Nar. 7-23 & Run on Task 5 \\
\hline $74-76$ & Mar. 24-26 & Full feed \\
\hline $77-79$ & Mar. 27-29 & Fed one hour per day \\
\hline $80-82$ & Mar. 30-April I & Run again on Task 1 \\
\hline
\end{tabular}




\section{BIBLIOGRAPHY}

1. Blodgett, $\mathrm{H}_{\text {., }}$ and McCutchan, K. Place vs. response leaming in the simple T-maze. J. exp. Psychol., 1947, 37, 412-422.

2. Blodgett, $\mathrm{H}_{.}$, and McCutchan, $\mathrm{K}$. Relative strength of place and response learning in the $\mathrm{T}$-maze. J. comp. physiol. Psychol., $1948,41,17-24$.

3. Blodgett, H., McCutchen, K., and Mathews, R. Spatial leaming in the T-maze: The influence of direction, tum, and food location. J. exp. Psychol., 1949, 39, 800-809.

4. Brown, W. I., and Gentry, G. V. Visual perception and insight in rats. J. comp. physiol. Psychol., 1950, 43, 226-230.

5. Corey, S. M. Sex differences in maze learning by white rats. J. comp. psychol., 1930, 42, 439-442.

6. Galanter, E. H., and Shaw, W. Cue vs. reactive inhibition in place and response leaming. J. comp. physiol. Psychol., $1954,47,395-402$.

7. Galanter, E. H. Place and response learning: Leaming to alternate. J. comp. physiol. Psychol., 1955, 48, 17-18.

8. Gentry, G., Brown, W. I. and Kaplan, S. J. An experimental analysis of the spatial location hypothesis in learning. J. comp. physiol. Psychol., 1947, 40, 309-322.

9. Hanson, D. A. The influence of age and sex on reasoning. J. exp. Biol., 19.49, 26, 317-326.

10. Harsh, C.M. Disturbance and insight in rats. Iniver. Calif. Publ. in Psychol., 1937, 6, 163-168.

11. Hill, C. W., and Thune, L. E. Place and response leaming in the white rat under simplified and mutually isolated conditions. J. exp. Psychol., 1952, 43, 289-296.

12. Hull, C. I. The mechanism of the assembly of behavior segments in novel combinations suitable for problem solution. Psychol. Rev., 1935, 42, 219-244.

13. Keller, F. S. and Hill, I. M. Another insight experiment. J. genet. Psychol., 1936, 48, 484-489. 
14. Kendler, H. H., and Gasser, W. P. Variables in spatial learning I: Number of reinforcements during training. J. comp. physiol. Psychol., 1948, 41, 178-187.

15. McNemar, Q., and Stone, C. P. The sex differences in rats on three leaming tasks. J. comp. psychol., 1932, 14, 171-180.

16. McNemar, Q. Psychological statistics. New York: Wiley, 1949.

17. Maier, N. R. F. Reasoning in white rats. Comp. Psychol. Monog., $1929,6,1-93$.

18. Haier, N. R. F. In defense of reasoning in white rats. J. comp. Psychol., 1935, 19, 197-206.

19. Maier, N. R. F. and Schneirla, T. C. Principles of animal psychology. New York: MeGraw-Hili, 1935, pp. 460-469.

20. Restle, F. Discrimination of cues in mazes: A resolution of the place-vs-response question. Psychol. Rev., 1957, 64, 217-228.

21. Ritchie, B. F. Studies in spatial learning III: Two different paths to the same location and two paths to two different locations. J. exp. Psychol., 1947, 37, 25-38.

22. Ritchie, B. F., Aeschliman, B. and Pierce, P. Studies in spatial learning VIII: Place performance and the acquisition of place dispositions. J. comp. physiol. Psychol., 1950, 43, 73-85.

23. Ritchie, B. F., Hay, A. and Hare, R. Studies in spatial learning IX: A dispositional analysis of response performance. J. comp. physiol. Psychol., 1951, 44, 442-449.

21. Scharlock, D. P. The role of extramaze cues in place and response learning. J. exp. Psychol., 1955, 50, 249-254.

25. Thompson, M. E. and Thompson, J. P. Reactive inhibition as a factor in maze learning II: The role of reactive inhibition in studies of place learning vs, response learning. J. exp. Psychol., 1949, 39, 883-891.

26. Tolman, E. C. and Honzik, C. H. Insight in rats. Univer. Calif. Publ. Psychol., 1930, 4, 215-232.

27. Tolman, E. C., Ritchie, B. F. and Kalish, D. Studies in spatial leaming I: Orientation and the short-cut. J. exp. Psychol., $1946,36,13-24$. 
28. Tolman, E. C., Ritchle, B. F. and Kalish, D. Studies in spatial leaming II: Place leaming vs. response leaming. J. exp. Psychol., 1946, 36, 221-229.

29. Tolman, E. C., Ritchie, B. F. and Kalish, D. Studies in spatial leaming IV: The transfer of place leaming to other starting points. J. $\exp$. Psychol., 1947, 37, 39-47.

30. Tolman, E. C., Ritchie, B. F. and Kalish, D. Studies in spatial leaming V: Response learning vs. place leaming by the noncorrection method. J. exp. Psychol., 1947, 37, 285-292.

31. Tolman, E. C. and Gleitman, H. Studies in spatial leaming VII: Place and response learning under different degrees of motivation. J. exp. Psychol., 1949, 39, 653-659.

32. Tomlin, M. I. and Stone, C. P. Sex differences in learning abilities of albino rats. J. comp. Psychol., 1930, 16, 207-229.

33. Tryon, R, C. Studies in individual differences in maze ability II: The determination of individual differences by age, weight, sex and pignentation. J. comp. Psychol., 1931, 12, 1-22.

34. Waddell, D., Gans, S., Kempner, P. and Williams, A. A comparison of place and response learning in very joung rats. J. comp. physiol. Psychol., 1955, 48, 375-377.

35. Walker, E. I., Dember, W. N., Earl, R. W. and Karoly, A. J. Choice alternation I: Stimulus vs. place vs, response. J. comp. physiol. Psychol., 1955, 48, 19-23.

36. Webb, W. B. A study in place and response leaming as a discrimination behavior. J. comp. physiol. Psychol., 1951, 44 ,
263-268.

37. Wolfe, J. B. and Spragg, S. Some experimental tests of reasoning in white rats. J. comp. Psychol., 1934, 18, 455-469. 


\section{BIOGRAPHICAL ITEMS}

Leming Bassett Corlis was born in Cincinnati, Ohio on July 6, 1930. He attended public schools there until the age of eleven at which time his family moved to Melboume, Florida. He graduated from Melbourne High School in June, 1948. He entered the University of Florida that September and received the Bachelor of Arts degree with a major in psychology in February, 1953. He continued at the University in the Graduate School and obtained a Master of Arts degree with a psychology major in February of 1954. At the present time his future plans are indefinite. 
This dissertation was prepared under the direction of the chairman of the candidate's supervisory committee and has been approved by all members of the committee. It was submitted to the Dean of the College of Arts and Sciences and to the Graduate Council and was approved as partial fulfillment of the requirements for the degree of Doctor of Philosophy.

June 9, 1958
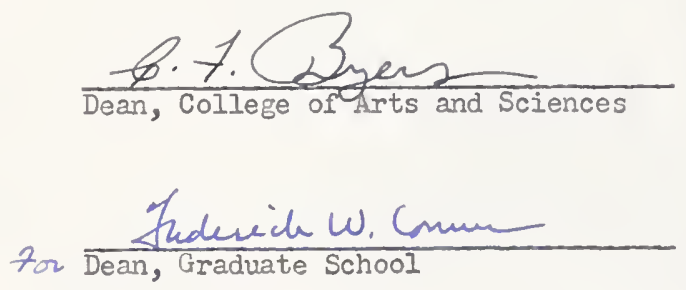

SUPERVISORY CONMITTEE:
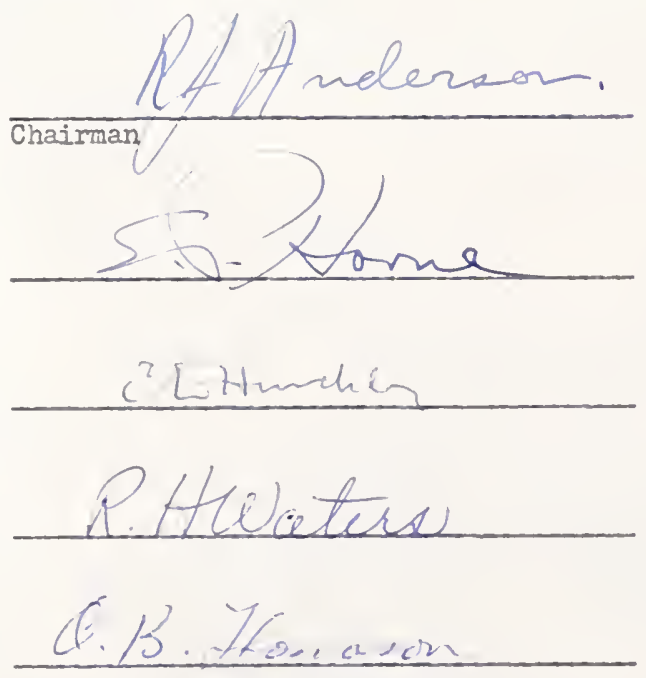
28710 